\title{
O LABORATÓRIO DIDÁTICO A PARTIR DA PERSPECTIVA DA MULTIMODALIDADE REPRESENTACIONAL
}

\author{
The didactic laboratory perspective \\ from multi-modal representation
}

\author{
Carlos Eduardo Laburú ${ }^{1}$ \\ Osmar Henrique Moura da Silva ${ }^{2}$
}

\begin{abstract}
Resumo: Este trabalho dá continuidade às reflexões existentes na literatura da área de educação científica que tratam do papel desempenhado pelo laboratório didático no ensino das ciências. Ao situar o laboratório didático a partir de uma perspectiva semiótica baseada no referencial da multimodalidade representacional, defende-se a importância desse espaço, na escola, para apropriação, consolidação e aprimoramento dos conceitos científicos. A ação experimental sobre e com os objetos do mundo natural e instrumentação envolvida é aqui ponderada como uma modalidade representacional que deveria compor o espectro multimodal de representações de ensino, com o objetivo de tornar o discurso e as ideias científicas mais integradas e significativas.
\end{abstract}

Palavras-chave: Laboratório didático. Análise semiótica. Ensino de ciências.

\begin{abstract}
This work gives continuity to the existent reflections in the literature of scientific education area that suport considerations about the function carried out by the didactic laboratory in the science teaching. When placing didactic laboratory in a semiotic perspective, based on the referential of the multi-modal representations, it is defended the importance of that space in the school for appropriation, consolidation and improvement of the scientific concepts. The experimental action on and with the objects of the natural world and implicated instrumentation it is here pondered as a representational modal that should compose the multi-modal representations spectrum in teaching with the objective to making the speech and scientific ideas integrated and significant.
\end{abstract}

Keywords: Didactic laboratory. Semiotic analysis. Science teaching.

1,2 Graduados em Física, doutores em Educação. Docentes, Departamento de Física, Universidade Estadual de Londrina (UEL). Londrina, PR, Brasil. <laburu@uel.br>, com apoio CNPq e Fundação Araucária;

<osmarh@uel.br>

${ }^{1}$ Departamento de Física, CCE/UEL

Caixa Postal 6001

Londrina, PR

86.051-970

721

Ciência $\mathfrak{E}^{3}$ Educação, v. 17, n. 3, p. 721-734, 2011 
Laburú, C. E.; Silva, O. H. M.

\section{Introdução}

Dentre as atividades de ensino e aprendizagem no ambiente escolar, as realizadas no laboratório didático sempre tomaram parte do espaço de discussão nas reflexões da área de educação científica. Trabalhos frequentemente surgem defendendo ou questionando a importância das práticas de laboratório para instrução científica (HODSON, 1994; WHITE, 1996). $\mathrm{Na}$ ponderação desse debate, constata-se substancial saldo positivo dos que reconhecem ou valorizam a importância das atividades de laboratório frente às críticas e defesa da ineficácia ou não-importância dessas atividades para aprendizagem.

Dando prosseguimento a esse debate, este trabalho pretende situar-se ao lado dos que defendem o laboratório didático e, de forma geral, as atividades empíricas que venham a ocorrer em espaços outros que não necessariamente nesse local. Para sustentar essa defesa, adentramos os fundamentos da atual linha de pesquisa em multimodalidade e múltiplas representações - linha essa que vem mostrando fortes indícios quanto aos seus méritos como estratégia instrucional para a aprendizagem dos conceitos científicos. $\mathrm{Na}$ apresentação das ideias que amparam o referencial da multimodalidade e múltiplas representações, pretendemos deixar evidente que as práticas experimentais de laboratório são consistentes com as suas orientações, com isso, temos a intenção de acrescentar um novo e complementar argumento para a importância do papel do laboratório didático.

Nas discussões abaixo, iniciamos por uma síntese das principais ideias que discorrem sobre o laboratório didático. Em seguida, introduzimos o referencial teórico da multimodalidade e múltiplas representações para justificar as atividades laboratoriais como um modo de representação auxiliador para elaboração dos conceitos científicos.

\section{O papel do laboratório didático}

Reflexões a respeito do laboratório didático vêm ocorrendo há bom tempo (NEDELSKY, 1958; MICHELS, 1965). Mas é nas últimas duas décadas e meia, aproximadamente, que se encontra, na literatura de educação científica, uma crescente e sistemática produção, investigando o assunto nos seus mais diversos pontos de vista, e que perpassa por todos os níveis de ensino. Em recente trabalho, Barolli, Laburú e Guridi (2010) oferecem um panorama das investigações que vêm envolvendo o laboratório didático. Os autores descrevem que o tema laboratório didático é tratado segundo os mais variados aspectos. Há estudos preocupados com a questão dos conteúdos específicos que só podem ser desenvolvidos na sala de laboratório, como o problema da medida, da determinação de constantes físicas ou das diversas abordagens didáticas que um determinado tipo de experimento pode fornecer. Existem os que enfatizam muito mais procedimentos e desenvolvimento de habilidades, como: o uso e manipulação acurada dos instrumentos e técnicas laboratoriais, de organização e comunicação, desenvoltura para questionar, pensar criticamente, resolver problemas, procurando debater a relação processo versus conteúdo. Alguns analisam os objetivos do laboratório, seu papel e características, ou ressaltam a estruturação didática, as etapas do método científico, a importância da introdução de experimentos fundamentais. Também existem aqueles que centram mais a atenção na natureza epistemológica e na relação desta com o ensino e aprendizagem. Há os que focalizam a dinâmica de grupo de estudantes no trabalho de laboratório por meio 
de referenciais psicanalíticos, ou que buscam métodos alternativos de avaliação dos estudantes mais apropriados às características pedagógicas desenvolvidas em ambiente de laboratório. Outros buscam identificar as dimensões do interesse, analisando o benefício de um experimento em termos dos resultados das atitudes dos alunos frente a um estilo de instrução mais aberto e questionador, se comparado a um estilo expositivo e mais fechado. Incluem-se, ainda, os que buscam as diferentes percepções dos alunos e professores a respeito do propósito do laboratório e que comparam o planejamento das atividades práticas com as razões para esse planejamento. Como exemplo final, encontramos estudos, como os de Tiberghien et al. (2001), que apontam as diferenciações e particularidades dos laboratórios de física, química e biologia; ou de Séré (2002), que se baseia na existência de grandes projetos internacionais que reúnem práticas comuns vinculadas a objetivos gerais dos diversos laboratórios do Ensino Médio e universitário de vários países da Europa.

Séré (2002) agrupa os diversos temas discorridos nas investigações acerca do laboratório didático no que ela denomina de clássicas categorias conceitual, epistemológica e procedimental, e que, segundo a autora, continuam oportunizando uma análise sintética das funções ou finalidades a que imaginam prestar o laboratório didático no ensino das ciências. Do ponto de vista de Barolli, Laburú e Guridi (2010), as potencialidades e funções do laboratório suscitam muitas reflexões e controvérsias, posto que seu papel sempre será uma questão polêmica para o ensino de ciências, porque a diferença mais radical entre as distintas concepções que podem ser encontradas na literatura reside tanto nas visões distintas de aprendizagem e do processo de construção do conhecimento, como nas possibilidades do uso do laboratório como instrumento de aquisição de conhecimento.

Tendo em consideração a relevância desta última colocação, passamos a , na seção abaixo, o referencial da multimodalidade representacional e múltiplas representações, que pretende situar o laboratório como importante espaço instrucional para ativar modos de representação distintos e complementares aos que podem ser empregados em outros espaços escolares de caráter mais expositivos, com o objetivo de promover a aprendizagem mais eficaz dos conceitos científicos. Então, independente da possível classificação que se possa vir a utilizar para organizar analiticamente a diversidade de argumentos e pressupostos que fundamentam as diferentes visões dos objetivos em torno do laboratório, os pressupostos baseados na multimodalidade representacional estão dirigidos para a maneira de se compreenderem os processos da ciência e da aprendizagem. Assim, o objetivo do uso do laboratório didático na aprendizagem científica justificar-se-á, neste trabalho, segundo uma dimensão cognitivista.

\section{Multimodalidade e múltiplas representações}

Dentre as linhas de pesquisa em educação científica, o referencial da multimodalidade representacional e múltiplas representações vem concentrando esforços para compreender e estimular a elaboração dos significados dos conceitos científicos pelos estudantes. Pesquisadores que investigam essa linha reconhecem que as disciplinas científicas são um histórico caminhar em direção ao desenvolvimento e integração de variadas formas discursivas, e que diferentes modos de representação servem a diferentes propósitos de pensamento e do inquirir científico. Por implicação, os estudantes deveriam aprender a respeito de cada forma de representação utilizada pela ciência, além de saber convertê-las e coordená-las dentro de um 
discurso consistente. Os pesquisadores, igualmente, estão de acordo com o fato de que, se os aprendizes não conseguem ao menos representar seus entendimentos em diversos modos, dificilmente seus conhecimentos se tornam suficientemente robustos e duráveis; mas, por outro lado, se os mesmos conceitos forem estimulados em variados modos e formas de representação, tal ação contribui para a ocorrência de apropriações conceituais mais profundas e permanentes (WALPRID; PRAIN; CAROLAN, 2010).

Antes de adentrarmos nos fundamentos dessa proposta, é preciso, a título de esclarecimento, comentar que Tyler, Prain e Peterson (2007) e Prain e Waldrip (2006), quando fazem alusão à multimodalidade representacional, estão querendo dizer que o discurso científico tem a propriedade de integrar diferentes modos de representar o raciocínio, processos e descobertas científicas. A referência dos autores ao termo múltiplas representações designa a prática de representar um mesmo conceito ou processo científico de diferentes maneiras. Contudo, em relação à multimodalidade representacional, Radford, Edwards e Arzarello (2009, p. 91) qualificam esse termo referindo-o a diversos meios ou "recursos perceptivos" em que as distintas formas representacionais podem vir a ser pensadas, comunicadas ou executadas. Todavia, para Blown e Bryce (2010), modalidade significa apenas uma referência a diferentes maneiras de compartilhar um significado. Aqui utilizamos ambos os termos nesses três sentidos indistintamente, sem comprometer a clareza do que estiver sendo falado.

Dito isso, entendemos que a consideração de cunho cognitivista multimodal e de múltiplas representações parte do princípio de que a apreensão e o diagnóstico do conhecimento científico prendem-se, essencialmente, às análises semióticas do seu sistema de produção e de suas representações. Maneiras de raciocinar e de visualizar por meio desses conhecimentos estão intrinsecamente ligadas à utilização de representações semióticas, e toda comunicação disciplinar se estabelece com base nelas.

Para que a aprendizagem em ciências se realize de maneira efetiva e engajada, é lugar comum das pesquisas contemporâneas em educação científica assegurarem, entre outras coisas, que os estudantes sejam desafiados a desenvolver um entendimento mais profundo dos significados em estudo, sem desconsiderar suas preferências e necessidades pessoais de aprendizagem. Para isso, é preciso que tarefas de avaliação sejam igualmente diversificadas quanto ao seu aspecto representacional, além de que a natureza desse conhecimento tenha relevância cultural, com implicações locais, sociais, pessoais ou tecnológicas. Mas para que haja profundidade dos significados, diferentes representações dos conceitos e processos científicos devem ser trabalhadas, e os estudantes devem ser capazes de transitar de maneira coordenada entre as representações envolvidas com o conhecimento científico (PRAIN; WALDRIP, 2006).

Como é próprio do discurso científico o emprego de diferentes linguagens, a construção de uma forte compreensão de um conceito permanece ligada à extração do significado imanente às várias representações; por conseguinte, é fundamental que os estudantes desenvolvam uma compreensão dos diversos modos de representá-lo, sem que se tornem dependentes de um modo particular ligado a um tópico específico (PRAIN; WALDRIP, 2006). Ora, um ambiente instrucional de ensino das ciências centrado em multimodos e múltiplas representações, inclusive que considera representações próprias informais (WALDRIP; PRAIN; CAROLAN, 2010), é consequência dessa abordagem.

Diferentes classificações dos modos de representação têm sido propostas (PRAIN; WALDRIP, 2006), mas existe certo consenso de que suas categorias incluem formas: descritivas (verbal, gráfica, tabular, diagramática, matemática), figurativas (pictórica, analógica ou 
metafórica), cinestésicas ou de gestos corporais (encenação, jogos), que usam objetos tridimensionais (3D) ou maquetes, experimentos etc.. Vários desses modos e formas de representação são usados individualmente e coordenadamente para representar as afirmações do discurso científico. As maneiras disciplinares de conhecer das várias ciências relevam, concentram e combinam modos e formas de representação que lhes são característicos. Conhecer uma disciplina é inseparável do domínio semiótico sobre o qual ela está edificada. Isto acarreta que uma parte significante da aprendizagem é vista através da necessidade de o aprendiz ir "descobrindo" o significado das representações discursivas empregadas pela disciplina estudada (AIREY; LINDER, 2009). Por exemplo, em Física, as representações matemáticas e gráficas são prioritárias à verbal, de forma que os conceitos dessa esfera de conhecimento são mais bem expressos e inteligíveis por meio daquelas linguagens; sem mencionar que, nas ciências da natureza, a modalidade representacional, baseada em experimentos, ações e procedimentos, ligados a um "saber fazer", tem lugar de destaque. Portanto, a relevância de certos modos semióticos em relação a outros fica na dependência do tipo de conhecimento estudado. Ademais, conforme o referencial da multimodalidade, para o educador científico, as variadas representações semióticas têm diversificado papel pedagógico, e, no caso da construção de significados científicos, o contato e manipulação com objetos e eventos têm importância cognitiva.

No âmbito pedagógico, então, ao se afirmar que um aprendiz está entendendo ou que aprendeu algo, significa dizer que ele, além de ser capaz de mobilizar os conhecimentos dentro e fora do contexto de cada representação ensinada, deve ser hábil na conversão de registros ou tradução entre quaisquer representações. Do ponto de vista semiótico, compreender envolve, em última instância, competência no trânsito intrarepresentação e inter-representação de um mesmo referente. Para Gardner (1995), a natureza do entendimento tem a ver com saber aplicar conhecimentos, e podemos saber se ele foi obtido quando se constata desempenho com sucesso nessa aplicação. Segundo o autor, para se saber se um aluno compreende um princípio da física, por exemplo, é necessário que se aprecie seu desempenho na construção ou conserto de um aparelho, no emprego correto de uma fórmula ou predição de um fenômeno (GARDNER, 1995, p. 165), e, para o que nos interessa enfatizar, realizar experimentos, no seu mais amplo sentido, para aplicar uma ideia ou conceito. Logo, entendimento tem um sentido multimodal, e tem a ver com a capacidade bem-sucedida na conversão e trânsito entre modos e formas representacionais de um conceito estudado.

O significado de uma mensagem se locupleta pela envergadura das diferentes modalidades semióticas, isto porque o significado encontra-se distribuído por entre as diversas representações e não é abarcado por uma única (JAIPAL, 2010, p. 50). Panaoura et al. (2007, p. 538) afirmam que é da diversidade de representações que surge o significado dado a um objeto seja ele matemático ou qualquer objeto cultural. A variabilidade dos sistemas representacionais e o trânsito entre eles são fundamentais para o entendimento conceitual e determinam, numa significante extensão, o que foi aprendido. Na medida em que cada representação de um conceito oferece informação sobre um traço peculiar dele, sem ser capaz de descrevêlo completamente (PANAOURA et al., 2007), formas variadas de representação conseguem prover distintas inferências. Isto porque cada representação apresenta natureza diversa da outra e proporciona restrita capacidade de representação e descrição de aspectos diferentes do referente (PANAOURA et al., 2007). Cada sistema de representação encerra propriedades específicas que limitam intrinsecamente suas possibilidades de representação. Treagust et al. (apud LEITES et al., 2008) comentam que se tem muitas formas de representar moléculas e 
átomos, cada uma delas é usada para destacar aspectos particulares do fato que se pretende explicar e nenhuma é universalmente aplicável. Os signos, de forma geral, não funcionam de maneira idêntica e nem provêem de um sistema único (BENVENISTE apud DUVAL, 2004), afinal toda representação é cognitivamente parcial em relação ao que representa e não apresenta idêntica maneira de ver um mesmo conteúdo conceitual. Consequentemente, cada sistema semiótico nos permite uma maneira distinta de significar sem que seja redundante (RADFORD et al. 2007).

Deve-se levar em consideração, também, que, na troca de representação, certos tratamentos são efetuados de uma maneira muito mais simples e mais potente do que outros. A importância da troca pode estar justamente em se conseguir efetuar um tratamento totalmente diferente em outro registro de representação distinto daquele em que foram dadas as representações iniciais. Sem dúvida, cálculos numéricos ou algébricos, a escrita decimal dos números e as notações literais são mais econômicos e potentes do que os feitos com a linguagem natural. Por sua vez, o poder heurístico das figuras vem do fato de os tratamentos figurativos que permitem executar não serem equivalentes aos raciocínios dedutivos estabelecidos por um teorema em forma escrita simbólica ou em língua natural. Por uma figura, diferentemente de um teorema ou definição, se é capaz de perceber objetos e relações em um espaço de dimensão superior àquele que o raciocínio explicita e necessita. A figura joga, pois, um papel heurístico ao permitir trabalhar numa dimensão superior à das unidades figurais que representam (DUVAL, 2004). Elas e os esquemas apresentam o mérito de representar a totalidade das relações entre os elementos constituintes do objeto ou da situação estudada. Ambos possibilitam modificações visuais proporcionais surgidas das relações das partes com o todo e que podem ser realizadas mentalmente ou fisicamente, independentes de qualquer conhecimento específico.

Porém, como qualquer representação, as figuras, assim como as representações analógicas, geométricas etc., apresentam limitações. Elas não conseguem representar mais do que estados, configurações ou produtos de operações, e não ações ou transformações (BRESSON apud DUVAL, 2004, p. 69). Para representar operações, é necessário possuir as propriedades de uma linguagem semelhante à linguística ou algébrica. Outra limitação encontra-se nas operações de modificação que se fazem necessárias na análise das figuras, onde existem fatores específicos para cada operação mais ou menos visíveis, que constituem a riqueza, mas, ao mesmo tempo, a complexidade das figuras geométricas e de outras. Nas resistências e armadilhas de uma figura subjazem fatores que são próprios a cada representação figural, como, por exemplo, a lei gestáltica do fechamento ou da continuidade dos estímulos visuais, lei esta que determina que contornos simples e fechados de uma figura geométrica sejam vistos separados como se fossem um todo, uma vez que predominam as unidades de dimensões maiores em relação às inferiores quando do estímulo visual (DUVAL, 2004).

Os diferentes atributos proporcionados pelas representações acima exemplificadas adicionados à qualidade topológica e tipológica, que serão descritas na próxima seção, dão sustentação cognitiva para que multimodos e múltiplas representações tenham valor pedagógico. Em complementação a isso, vemos que as múltiplas dimensões semióticas de que pode vir a se valer a aprendizagem do conhecimento científico mantêm-se subordinadas, ainda, a um duplo, interdependente e inerente aspecto comum a toda comunicação, que são: a) Não há significação completa por si própria, mas ela permanece dependente de diferentes fontes de informação e de um domínio contextual de experiências e significados. As circunstâncias, entendidas como todos os fatos conhecidos pelo receptor de uma mensagem, favorecem diferen- 
temente as diversas mensagens admitidas pelo sinal que o emissor tenta transmitir, o que significa que a atenção do receptor deveria estar dirigida para elas (PIETRO, 1973). Por consequência, toda comunicação faz assunções sobre o que o destinatário deverá saber, tomando-as como base para ulterior interpretação (PIETRO, 1973). Nessa mesma direção, Grize (apud DUVAL, 2004) complementa dizendo que não pode haver discurso cuja elaboração não leve em conta as representações reais ou supostas do seu destinatário presente ou virtual. Na verdade, no entender de Eco (2003), estamos continuamente a antecipar as expressões de outrem, preenchendo espaços vazios dos textos, prevendo ou pressupondo palavras que o interlocutor dirá ou não deveria ter dito, ou que nunca mesmo dirá. Mesmo simples proposições têm mais que um sentido, pois o seu status, que determina o lugar de uma proposição na organização discursiva de um conjunto de proposições ou o papel que joga na expansão discursiva, depende do contexto da enunciação (DUVAL, 2004) ou contexto psicológico (OGDAN; RICHARDS, 1989); b) Todo aquele que realiza uma interpretação acha um caminho diferente para o significado (LEMKE, 2003). Por isso, os indivíduos não interpretam um texto de maneira semelhante, visto que partem de diferentes condições iniciais de conhecimentos, experiências e habilidades. Além disso, a dinâmica em sala de aula é corrida e dá-se em torno de um complexo ambiente, onde vários acontecimentos ocorrem simultaneamente. Isto faz com que frequentes falhas de comunicação do professor com seus alunos aconteçam, sendo possível presenciar informações erradas, incompletas, insuficientes, ausentes, confusas, mal localizadas e escritas, às vezes, adiantadas ao conteúdo de interesse, inconvenientemente misturadas, com defasagens temporais de conhecimentos dos aprendizes etc. Para o estudante, acaba ficando o malabarismo da difícil tarefa de selecionar e unir a informação correta num todo coerente e sintético e chegar à compreensão do que o professor pretende. Afortunadamente, a linguagem humana é um sistema tolerante às faltas e incorpora uma grande redundância, especialmente quando se considera uma média num longo período de tempo. Para um mecanismo de autocorreção funcionar durante a aprendizagem, os estudantes precisam ser capazes de integrar significados daquilo que está sendo comunicado e, para isso, é vital que o professor utilize diferentes sistemas semióticos, como recurso de comunicação (LEMKE, 2003). Decorre daí oportunizar que modos de comunicação já percorridos sejam repetidos, revistos, corrigidos, aprofundados, integrados e coordenados a outros, favorecendo a ultrapassagem das falhas mencionadas.

As colocações anteriores justificam, de modo natural, uma orientação para várias formas e modos de representação em interlocuções do professor com os estudantes, visto que as mesmas não são completas e estão longe de serem prolixas. Esse traço da comunicação humana e, particularmente, da científica, conduz a que um significado somente se vê preenchido por integração de um somatório de significados levados pelas várias formas e modos comunicativos, sem que se desconsiderem os já elaborados no passado. Ora, o significado de cada palavra se enriquece pelo acúmulo do encontro de diferentes contextos, pela intersecção de muitas afirmações e pela confluência de muitos tipos, formas e modos discursivos. Toda palavra, assim como cada figura, digrama, equação, simbolismo envolvido por detrás das ações e procedimentos promovidos por experimentos etc., pertence a um contexto e é parte de uma possível troca de significados entre diferentes membros de uma determinada comunidade.

É preciso acrescentar que, para cada sujeito, há um caminho particular para a construção de significados. Consequentemente, um ensino plural em termos representacionais é compatível com o princípio pedagógico contemporâneo, que atenta para as necessidades e preferências individuais cognitivas, quando se pensa numa aprendizagem efetiva. Está-se a dizer com 
Laburú, C. E.; Silva, O. H. M.

isso que um determinado modo representativo tem potencial de se tornar mais eficaz para iniciar ou aprimorar a elaboração das ideias de um particular aluno, auxiliando-o a ultrapassar obstáculos conceituais de representações mais abstratas e oficiais. A razão para assim ser permanece atrelada às habilidades ou capacidade humana diferenciada e à história cognitiva construídas por cada sujeito no instante instrucional específico. Um modo representacional é capaz, então, de se comportar tal qual um "andaime conceitual", ao prover um apoio auxiliar para o sujeito construir o conceito almejado, assistindo-o na elaboração de novas representações.

Para Ainsworth (apud PRAIN; WALDRIP, 2006), o engajamento em uma pluralidade de modos e formas representacionais sustenta a aprendizagem por três motivos: é conveniente para complementar ou reforçar, por confirmação, conhecimentos passados; propicia, por restrição, o refinamento de uma interpretação ao limitar o foco do aprendiz sobre conceitos fundamentais; capacita-o a identificar um conceito ou abstração subjacente entre os modos ou dentro do mesmo modo de representação. Dentro das considerações que vimos fazendo anteriormente, a esses três motivos acrescentemos mais dois: determinados modos podem se adequar melhor a certos indivíduos, por servir-lhes de meio apropriado para compreender um conceito, devido à existência de esquemas conceituais já construídos por eles; a relação de ordem emocional que os aprendizes mantêm com o conhecimento é própria a cada um.

Como última ponderação a respeito do referencial multimodal, indiquemos sua capacidade em proporcionar redes conceituais, as quais estão vinculadas diretamente com o entendimento. Quando os estudantes examinam diferentes representações da mesma ideia, estão, na verdade, construindo redes conceituais. Para Duval (2004), Ausubel (apud MOREIRA, 1999) e Ainsworth (apud PRAIN; WALDRIP, 2006), a aprendizagem com entendimento ou significativa é alcançada quando o aprendiz consegue mostrar desempenho na conversão e comunica equivalência de significados entre distintas representações, ao mesmo tempo em que é capaz de integrá-los em um discurso multimodal de representação, de tal forma que não permaneça dependente de um signo particular ou modo exclusivo de expressão. De fato, o termo "estabelecer conexões" encontra-se no cerne das reflexões colocadas ou delas é decorrente, na medida em que espelha a importância de se constituírem relações sobre o conhecimento. É pelo uso intencional de "resemiotizações" e negociação das transformações semióticas que se leva à construção de conexões para instaurar significâncias (STEINBRING, 2006). Os aprendizes, ao criarem conexões referenciais entre elementos e estruturas correspondentes em diferentes representações, estão construindo vinculações nas e entre as diferentes representações, e só assim são capazes de adquirir um mais profundo entendimento (HAND; GUNEL; ULU, 2009). Portanto, potencializa-se uma aprendizagem aprofundada e significativa, na medida em que maior número de relações e conexões construídas é favorecido, o que permite outorgar significados e funcionalidade aos novos conceitos e princípios aprendidos (PATTERSON; NORWOOD, 2004).

\section{Atividades no laboratório didático e a produção de significados}

$\mathrm{Na}$ seção anterior, delineamos argumentos que dão sustentação à estratégia baseada no referencial multimodal e de múltiplas representações. Vimos que ela fornece condições para a produção dos significados dos conceitos científicos sempre que o aprendiz dispuser de múltiplas formas semióticas para tratar uma informação, conforme também lembra Perales Palaci- 
os (2006, p. 19a). Entender um conceito científico significa menos conhecer as exatas palavras expressas e sua definição, do que conhecer e usar apropriadamente seus distintos recursos representacionais para realizar ligações cognitivas entre teoria e fenômeno. De fato, o significado de palavras, conceitos, proposições, leis etc. científicos se encontra incrustado nos elementos representacionais formadores do discurso, e apreender é um ato de compor a totalidade do significado manifesta por um conjunto de multiplicidades semióticas, visto que cada uma é capaz de apreender uma particularidade dessa totalidade.

A partir deste momento, passemos a posicionar o laboratório didático como espaço privilegiado de geração de um modo representacional que se concentra na esfera do sensível ou corporal, modalidade esta que envolve necessariamente movimentação corporal, como gestos, ações e procedimentos experimentais. Por ser um lugar aparelhado para realização empírica, é da natureza desse espaço ativar modos de representação diferenciados daqueles normalmente usados fora desse ambiente. Por essa razão, tais modos levam à estimulação de processos cognitivos específicos para a construção dos significados ensinados, com reflexos para a produção do entendimento conceitual.

Entre os multimodos empregados para representar os raciocínios e os achados científicos, a cinesia, em particular - que é a faculdade de imprimir movimento aos membros -, cumpre um papel singular, quando se trata de aprender de maneira integrada os vários conceitos e formas de representar o discurso das ciências da natureza. Como já é possível perceber, cinesia se refere a toda ação corporal utilizada durante o discurso científico, que expressa sinais carregados de significados (WALDRIP; PRAIN; CAROLAN, 2006) e que, no ambiente de laboratório, está fundamentalmente implicada com ações sobre materiais concretos. No caso da educação científica, a importância desse modo de representação fica proeminente nas atividades empíricas, por meio de procedimentos e habilidades experimentais, condutas e manipulação com/e sobre os objetos.

Os gestos, assim como as expressões verbais, são exemplos de representações. Peirce leva a noção de representação sígnica tão longe que a mesma não precisa ter natureza plena de uma linguagem (palavras, desenhos, diagramas, fotos etc.), mas pode estar expressa em: uma mera ação ou reação (p.ex., correr para alcançar alguém), uma simples emoção, ou qualquer sentimento como, por exemplo, a qualidade vaga de sentir ternura, desejo, raiva, dor etc.. Por conseguinte, ao serem externadas, emoções, ações, reações, entre outras experiências, dão corpo aos pensamentos (SANTAELLA, 2005) produzindo significados.

Alguns autores creem que essas representações apenas servem para facilitar os modos verbais. Outros imaginam que elas têm uma função substitutiva para um item léxico temporariamente inacessível. Há, ainda, aqueles que defendem que os gestos corporais e a fala são partes da mesma fonte cognitiva, sendo capazes de revelar aspectos do conteúdo mental ao mostrarem os pensamentos internos e maneiras de entender os eventos do mundo do falante - assim, funcionariam como janelas para acessar o pensamento (RADFORD, 2009). Tais perspectivas pertencem a uma longa tradição estabelecida que vê o pensamento como sendo uma atividade puramente mental, algo imaterial, impalpável, que ocorre independente do corpo e atua unicamente na cabeça. Numa perspectiva diferente, a atividade mental deixa de ocorrer somente na cabeça, mas também ocorre na/ e através de uma sofisticada coordenação da fala, corpo, gestos, símbolos, ações e reações, sobre ferramentas e sobre o meio natural. De acordo com esse ponto de vista, qualquer atividade corpórea tem relevância cognitiva. Então, na ocorrência de alguma coisa que possa vir a iluminar o intricado pensamento cientí- 
Laburú, C. E.; Silva, O. H. M.

fico e matemático dos estudantes e a profundidade de seus conhecimentos, esta deve ser buscada em gestos, olhares, ações, habilidades, procedimentos e outras produções semióticas, e não apenas em modalidades verbais padronizadas (O'BYRNE, 2009).

Em Gehlen (apud RADFORD, 2009), vemos que o ato de conhecer só é capaz de ser assegurado por meio de uma experiência multissensorial do mundo e por um tipo de apreensão autossensorial das coisas. Já em 1923, Ogdan e Richards (1989, p. 49) reconheciam que

As mais importantes classes de coisas com as quais temos conhecimento direto são nossas próprias sensações, que podem ser chamadas experiências, as ideias e significados, sobre os quais temos nossos pensamentos e que podem ser chamados entendimento, e os fatos ou características ou relações dos dados do sentido ou significados, que podem ser chamados de percepção.

O conhecimento dos objetos decorre de uma complexa e variada representação sensorial e de um cruzamento plurirrepresentacional em que a tomada de consciência é multissensorial e multicognitiva. A plasticidade e a colaboração dos vários sentidos humanos contribuem para essa apreensão. A compreensão inicial mais completa de um objeto, como, por exemplo, uma vara, passa pela avaliação visual de seu comprimento, mas sua rigidez ou peso apenas podem ser abstraídos por meio de uma experiência tátil, contando pouco o visual. Por isso, cada representação suporta processos cognitivos que são mais ou menos fáceis de realizar em um sistema semiótico do que em outros. Enquanto certas representações carregam uma composição mais apropriada para conceituar significados topológicos, outras são mais adequadas para conceituar significados tipológicos. Um exemplo deste último é a linguagem verbal. A característica tipológica é mais poderosa para expressar raciocínios semânticos, qualificar ideias ou realizar relações entre categorias. Opera, primariamente, por contrastes entre aspectos mutuamente exclusivos, sendo relativamente limitada e com poucos recursos para expressar significados quantitativos ou de grau. Por outro lado, quando se faz necessário estabelecer referências quantitativas, que necessitam expressar grau, as linguagens topológicas de tipo visual, como gestos, desenhos, e a prática experimental que nos interessa ressaltar, são recursos semióticos que melhor exprimem significados desta natureza e apresentam maior eficácia de tratamento do que a linguagem tipológica (PRAIN; WALDRIP, 2006; LEMKE, 2003).

Nesse sentido, em tom de crítica, Mäntylä e Koponen (2007) alegam que a formação das quantidades, por meio de experimentos quantitativos, frequentemente não é vista como parte da compreensão conceitual, nem ao menos é tratada como parte não problemática desta. Yore e Hand (2010) apontam que a transformação entre as modalidades representacionais como fazer medidas e coletar dados, esquematizar e organizar tabelas, gráficos, diagramas, descrições orais ou impressas para projeção - encorajam maior processamento e melhor compreensão das ideias arraigadas. Mais especificamente, para Klein e Kirkpatrick (2010), a medição é a "ressemiotização" da percepção de um atributo em um conjunto de signos numéricos. Visualizações, tais como gráficos, transformam dados numéricos em novas formas representacionais a partir dos quais as relações entre variáveis podem, frequentemente, ser aprendidas de maneira perceptual. Acrescente-se, ainda, que conceituar grandezas físicas de modo integral envolve relacioná-las de maneira consistente em um sistema de representações formais, assim como saber convertê-las nos modos de representação gestuais via ação, procedimentos, habilidades ou 
atitudes, e vice-versa. A possibilidade bem-sucedida de conversão entre modos de tipo manipulativo, formais (verbal, matemática) e outras representações semióticas (tabelas, diagramas, gráficos) determina, até mesmo, se uma grandeza física foi significativamente aprendida.

Pelas colocações precedentes, fica estabelecido que as atividades manipulativas e de percepção sobre o real são semiotizações que estendem, complementam, aprimoram e refinam a capacidade cognitiva do aprendiz em tratar os abstratos conceitos da ciência. Com elas, procura-se evitar que o conhecimento científico se disponha em fragmentos isolados e descorrelacionados. Potencializa-se, portanto, uma aprendizagem mais aprofundada e significativa, em que maior número de relações e conexões construídas é favorecido, o que torna possível outorgar significados e funcionalidade aos novos conceitos e princípios aprendidos.

Assim, dentro de uma leitura semiótica, da qual toma parte o referencial multimodal, sempre que nos expressamos em qualquer sistema de sinais, há reciprocidade e conjunção dinâmica entre expressar através da forma, refletir através do conteúdo e condução de um ato (ORGSTAD, 2006). Enfim, a aprendizagem do conhecimento das ciências da natureza não se revela por uma mera leitura e meditação a respeito dos símbolos e princípios, mas sua interpretação e reflexão surgem, igualmente, das ações sobre o mundo natural e instrumentos tecnológicos. Ou, como reporta sinteticamente Lemke (2003), todo conceito científico é, simultaneamente, um sinal em um discurso semântico verbal e em um sistema operacional de significados de ação.

\section{Conclusões}

As ponderações retiradas do referencial da multimodalidade e múltiplas representações trazem novos argumentos a favor da importância instrucional de se promover o ensino de ciências com inclusão de atividades empíricas em laboratório como meio de promoção da pluralidade semiótica para interiorizar e consolidar conceitos científicos. Como parte da miríade representacional que pode ser usada no ensino, inclui-se a que envolve objetos reais, dado que a cinesia e a atuação sobre/e com materiais é um modo de representação do qual o pensamento toma parte para a construção conceitual. Dentro disso, a prática experimental em laboratório, objeto de interesse deste trabalho, é um modo representacional fundamental a se destacar para auxiliar e complementar a construção dos processos e conceitos científicos, os quais permanecem sustentados nas escolas, quase sempre, por exposições fixadas em modos de representações formais.

Concluímos que a estimulação do modo representacional experimental deve ser observada como imperativa para o ensino das ciências, não apenas por retratar a natureza epistemológica do conhecimento científico, mas por carregar uma característica pedagógica cognitivamente singular, que, em combinação com outros modos e formas representacionais, apoia, complementa e aprimora a formação do pensamento científico. Desta forma, o significado por detrás de uma ideia ou processo se locupleta conforme a envergadura alcançada pelas diferentes representações a serem utilizadas.

Como consideração final, do ponto de vista da aprendizagem dos estudantes, destacamos a relevância das reflexões acima para os trabalhos que se preocupam em produzir um conhecimento mais completo sobre aquilo que é o papel do laboratório didático. Ao mesmo tempo, esperamos estar dando uma contribuição para tornar mais produtiva a discussão em 
Laburú, C. E.; Silva, O. H. M.

torno do tema laboratório didático, defendendo-o como um espaço escolar para mobilizar, instigar e explorar a inteligência dos aprendizes especificamente ligada ao fazer e ao agir.

\section{Referências}

AIREY, J.; LINDER, C. A disciplinary discourse perspective on university science learning: achieving fluency in critical constellation of modes. Journal of Research in Science Teaching, Hoboken, v. 46, n. 1, p. 27-49, 2009.

BAROLLI, E.; LABURÚ, C. E.; GURIDI, V. Laboratorio didáctico de ciencias: caminos de investigación. Revista Electrónica de Enseñanza de las Ciencias, Vigo, v. 9, n. 1, p. $88-110,2010$.

BLOWN, E.; BRYCE, T. G. K. Conceptual coherence revealed in multi-modal representations of astronomy knowledge. International Journal of Science Education, Abingdon, v. 32, n. 1, p. 31-67, 2010.

DUVAL, R. Semiosis y pensamiento humano: registros semióticos y aprendizajes intelectuales. Santiago de Cali: Universidad del Valle, Instituto de Educación y Pedagogía, 2004.

ECO, H. Tratado geral de semiótica. São Paulo: Perspectiva, 2003. (Estudos, 73).

GARDNER, H. Inteligências múltiplas: a teoria na prática. Porto Alegre: Artmed, 1995.

HAND, B.; GUNEL, M.; ULU, C. Sequencing embedded multimodal representations in a writing to learn approach to the teaching of electricity. Journal of Research in Science Teaching, Hoboken, v. 46, n. 3, p. 225-247, 2009.

HODSON, D. Hacia un enfoque más crítico del trabajo de laboratorio. Enseñanza de las Ciencias, Barcelona, v. 12, n. 3, p. 299-313, 1994.

JAIPAL, K. Meaning making through multiple modalities in a biology classroom: a multimodal semiotics discourse analysis. Science Education, Hoboken, v. 94, n. 1, p. 48-72, 2010.

KLEIN, P. D. Rethinking the multiplicity of cognitive resources and curricular representations: alternatives to "learning styles" and "multiple intelligences". Journal of Curriculum Studies, Abingdon, v. 35, n. 1, p. 45-81, 2003.

KLEIN, P. D.; KIRKPATRICK, L. Multimodal literacies in science: currency, coherence and focus. Research in Science Education, Dordrecht, v. 40, n. 1, p. 87-92, 2010.

LEITES, L. M.; BERNARROCH, B. A.; PERALES, F. J. P. Las imágenes sobre enlace químico usadas en los libros de texto de educación secundaria. Análisis desde los resultados de la investigación educativa. Enseñanza de las Ciencias, Barcelona, v. 26, n. 2, p. 153-176, 2008. 
O laboratório didático a partir da perspectiva ...

LEMKE, J. L. Teaching all the languages of science: words, symbols, images, and actions. Disponível em: <http://academic.brooklyn.cuny.edu/education/jlemke/papers/ barcelon.htm>. Acesso em: 1 fev. 2007.

MÄNTYLÄ, T.; KOPONEN, I. T. Understanding the role of measurements in creating physical quantities: a case study of learning to quantify temperature in physics teacher education. Science and Education, Hoboken, v. 16, n. 3-5, p. 291-311, 2007. Disponível em: <http://per.physics.helsinki.fi/eng/publications/articles/temperature_IHPST8_ handout.pdf>. Acesso em: 1 fev. 2007.

MICHELS, P. B. The role of experimental work. American Journal of Physics, College Park, v. 30, n. 3, p. 172-178, 1965.

MOREIRA, M. A. Aprendizagem significativa. Brasília: Editora Universidade de Brasília, 1999.

NEDELSKY, L. Introductory physics laboratory. American Journal of Physics, College Park, v. 26, n. 2, p. 51-59, 1958.

O'BYRNE, B. Knowing more than words can say: using multimodal assessment tools to excave and construct knowledge about wolves. International Journal of Science and Mathematics Education, Dordrecht, v. 31, n. 4, p. 523-539, 2009.

OGDAN, C. K.; RICHARDS, I. A. The meaning of meaning. New York: Harcourt Brace Iovanovich, 1989.

ORGSTAD, S. Mathematics and mathematics education as triadic communication? A semiotic framework exemplified. Education Studies in Mathematics, Dordrecht, v. 61, n. 1-2, p. 247-277, 2006.

PANAOURA, I. E.; ERACLEOUS, A.; GAGATIS, A. Relations between secondary pupils' conceptions about functions and problem solving in different representations.

International Journal of Science and Mathematics Education, Dordrecht, v. 5, n. 3, p. 533-556, 2007.

PATTERSON, N. D.; NORWOOD, K. S. A case study of teacher beliefs on students' beliefs about multiple representations. International Journal of Science and

Mathematics Education, Dordrecht, v. 2, n. 1, p. 5-23, 2004.

PERALES PALACIOS, F. J. Uso (y abuso) de la imagen en la enseñanza de las ciencias. Enseñanza de las Ciencias, Barcelona, v. 24, n. 1, p. 13-30, 2006.

PIETRO, L. J. Mensagens e sinais. São Paulo: Cultrix/EDUSP, 1973.

PRAIN, V.; WALDRIP, B. An exploratory study of teachers' and students' use of multi-modal representations of concepts in primary science. International Journal of Science Education, Abingdon, v. 28, n. 15, p. 1843-1866, 2006.

RADFORD, L. Why do gestures matter? Sensuous cognition and the palpability of mathematical meanings. Educational Studies in Mathematics, Dordrecht, v. 70, n. 2, p. 111-126, 2009. 
Laburú, C. E.; Silva, O. H. M.

RADFORD, L.; BARDINI, C.; SABENA, C. Perceiving the general: the multisemiotic dimension of student's algebraic activity. Journal for Research in Mathematics

Education, Reston, v. 38, n. 5, p. 507-530, 2007.

RADFORD, L.; EDWARDS, L.; ARZARELLO, F. Introduction: beyond words.

Educational Studies in Mathematics, Dordrecht, v. 70, n. 2, p. 91-95, 2009.

SANTAELLA, L. Semiótica aplicada. São Paulo: Thomson, 2005.

SÉRÉ, M-G. Towards renewed research questions from the outcomes of the european project labwork in science education. Science Education, Hoboken, v. 86, n. 5, p. 624-644, 2002 .

STEINBRING, H. What makes a sign a mathematical sign? An epistemological perspective on mathematical interaction. Education Studies in Mathematics, Dordrecht, v. 61, n. 1-2, p. 133-162, 2006. Disponível em: < http://www.math.uncc.edu/ sae/dg3/abstractsdgpme26.pdf>. Acesso em: 1 fev. 2007.

TIBERGHIEN, A. et al. An analysis of labwork tasks used in science teaching at upper secondary school and university levels in several european countries. Science Education, Hoboken, v. 85, n. 5, p. 483-508, 2001.

TYLER, R.; PRAIN, V.; PETERSON, S. Representational issues in students learning about evaporation. Research in Science Education, Dordrecht, v. 37, n. 3, p. 313-331, 2007.

WALDRIP, B.; PRAIN, V.; CAROLAN, J. Learning junior secondary science through multi-modal representations. Electronic Journal of Science Education, Georgetown, v. 11, n. 1, p. 87-107, 2006.

. Using multi-modal representations to improve learning in junior secondary science.

Research in Science Education, Dordrecht, v. 40, n. 1, p. 65-80, 2010.

WHITE, R. T. The link between the laboratory and learning. International Journal of Science Education, Abingdon, v. 18, n. 7, p. 761-774, 1996.

YORE, D. L.; HAND, B. Epilogue: plotting a research agenda for multiple representations, multiple modality, and multimodal representational competency. Research in Science Education, Dordrecht, v. 40, n. 1, p. 93-101, 2010.

Artigo recebido em 04/10/2010. Aceito em 06/01/2011. 